\title{
Value of gas exchange recording at home in children receiving noninvasive ventilation
}

\begin{tabular}{|r|l|}
\hline Journal: & Pediatric Pulmonology \\
\hline Manuscript ID: & PPUL-10-0206.R2 \\
\hline Wiley - Manuscript type: & Original Article \\
\hline Date Submitted by the & 19 -Oct-2010 \\
\hline Complete List of Authors: & $\begin{array}{l}\text { Felemban, Osama; Faculty of Medicine, King Abdulaziz University, } \\
\text { Pediatric department } \\
\text { Leroux, Karl; ADEP Assistance } \\
\text { Aubertin, Guillaume; AP-HP, Hôpital Armand-Trousseau, Pediatric } \\
\text { Pulmonary Department } \\
\text { Miandy, Fabrice; ADEP Assistance } \\
\text { Damagnez, Frederic; ADEP Assistance } \\
\text { Amorim, Bruno; ADEP Assistance } \\
\text { Ramirez, Adriana; AP-HP, Hôpital Armand-Trousseau, Pediatric } \\
\text { Pulmonary Department } \\
\text { Fauroux, Brigitte; Armand Trousseau Hospital, Pediatric } \\
\text { pulmonology and INSERM U 719 }\end{array}$ \\
\hline Keywords: & $\begin{array}{l}\text { noninvasive ventilation, carbon dioxide, pulse oximetry, home, gas } \\
\text { exchange }\end{array}$ \\
\hline \hline
\end{tabular}

\section{SCHOLARONE ${ }^{\text {m }}$ \\ Manuscripts}




\section{Value of gas exchange recording at home in children receiving noninvasive ventilation}

Osama Felemban ${ }^{1,2}, \mathrm{MD}$, Karl Leroux ${ }^{3}, \mathrm{AAS}$, Guillaume Aubertin ${ }^{2}, \mathrm{MD}$, Fabrice Miandy ${ }^{3}$, AAS, Frédéric Damagnez ${ }^{3}$, AAS, Bruno Amorim ${ }^{3}$, AAS, Adriana Ramirez ${ }^{2}, A A S$, Brigitte Fauroux ${ }^{2,4}, M D, P h D$

${ }^{1}$ University Hospital, Faculty of Medicine, King Abdulaziz University, Jeddah 21589, Kingdom of Saudi Arabia

${ }^{2}$ AP-HP, Hôpital Armand Trousseau, Pediatric Pulmonary Department, Paris, France

${ }^{3}$ ADEP Assistance, Suresnes, Paris, France

${ }^{4}$ Université Pierre et Marie Curie-Paris 6 and INSERM UMR S-938, Paris, France

Correspondence to:

Pr. Brigitte Fauroux, MD, PhD

AP-HP, Hôpital Armand-Trousseau

Pediatric Pulmonary Department

Research unit INSERM UMR S-938

National reference center for rare lung diseases

Université Pierre et Marie Curie-Paris 6

26 avenue du Docteur Arnold-Netter

Paris, F-75012 France

Fax: $+33(0) 144736174$

Tel: $+33(0) 144736718$

Email: brigitte.fauroux@trs.aphp.fr

\section{Supports and grants}

The research of Brigitte Fauroux is supported by the Association Française contre les Myopathies (AFM), Assistance Publique-Hôpitaux de Paris, Inserm, ADEP Assistance, and Université Pierre et Marie Curie-Paris 6.

Running head: Gas exchange during noninvasive ventilation

Word count of the body of the manuscript: 2511 


\section{Abstract}

Noninvasive positive pressure ventilation (NPPV) is preferentially performed at home. The objectives of the study were to evaluate the feasibility of an overnight gas exchange recording at home and to compare recordings performed in the hospital and at home.

Twenty nine pairs of overnight gas exchange recordings during NPPV were performed at home and in the hospital in 11 children with neuromuscular disease and 13 children with other disorders treated with long term NPPV.

No technical problem occurred during the recordings performed at home and one pulse oximetry $\left(\mathrm{SpO}_{2}\right)$ recording failed in the hospital. For the two groups, $\mathrm{SpO}_{2}$ and transcutaneous carbon dioxide $\left(\mathrm{PtcCO}_{2}\right)$ values did not differ significantly between the hospital and the home. However, correlations between $\mathrm{SpO}_{2}$ and $\mathrm{PtcCO}_{2}$ values obtained in the hospital and at home were better for mean values than for minimal and maximal values, and in patients with other disorders as compared to patients with neuromuscular disease.

Overnight gas exchange recordings with NPPV by a combined $\mathrm{PtcCO}_{2} / \mathrm{SpO}_{2}$ monitor are feasible at home and show results comparable to hospital recordings. Home $\mathrm{PtcCO}_{2} / \mathrm{SpO}_{2}$ recordings may be integrated in the care of children treated with domiciliary NPPV and are associated with less disruption of family life and decreased health care costs.

\section{Word count of the abstract: 204}

Key words: carbon dioxide, child, gas exchange, home, noninvasive positive pressure ventilation, pulse oximetry. 


\section{Introduction}

Noninvasive positive pressure ventilation (NPPV) is increasingly used in children presenting various diseases which may cause alveolar hypoventilation such as neuromuscular or lung disease, thoracic deformities, severe upper airway obstruction, or disorders of ventilatory control ${ }^{1,2}$. The main advantage of NPPV is that this technique may be used on demand, preferentially at night, with minimal disruption of normal life. After appropriate training of the family and caregivers, the majority of the children may be discharged home. Regular clinical and physiological follow up is necessary in order to adapt the NPPV modes and settings to the patient's clinical status and growth, and to check any side effect or respiratory or maxillofacial complication.

We have recently demonstrated the importance of a systematic overnight combined pulse oximetry $\left(\mathrm{SpO}_{2}\right)$ and carbon dioxide $\left(\mathrm{CO}_{2}\right)$ recording, even in patients in a stable condition without any symptom or sign of alveolar hypoventilation ${ }^{3}$. Indeed, $42 \%$ of 50 children who were well acclimatized to NPPV, without evidence of symptoms of sleep disordered breathing, were hypercapnic, defined by a maximal transcutaneous $\mathrm{CO}_{2}\left(\mathrm{PtcCO}_{2}\right)$ value $>50 \mathrm{mmHg}$ during sleep. Most importantly, this nocturnal hypercapnia was not associated with nocturnal hypoxemia, defined by a minimal $\mathrm{SpO}_{2}<92 \%$, or abnormal daytime blood gases in $36 \%$ of the patients.

Repeated overnight hospitalizations are associated with disruption of family life and increased health care costs. Because of a general reduction in number of pediatric hospital beds, the transfer of selected, programmed, and well-organized activities or investigations from the hospital to the home is strongly encouraged. However, the feasibility, defined by the ability to obtain technically acceptable 
overnight recordings as well as the satisfaction of the parents with regard to their preference between hospital and home, and accuracy of these investigations performed in a home environment, should be evaluated before their wide spread use.

The aim of the present study was first to evaluate the feasibility of an overnight gas exchange recording by a combined transcutaneous $\mathrm{CO}_{2}$ and pulse oximetry $\left(\mathrm{PtcCO}_{2} / \mathrm{SpO}_{2}\right)$ monitor at home, and second to compare the results and costs of recordings performed in the hospital and at home in a cohort of stable children, treated at home with long term NPPV.

\section{Material and methods}

Patients

Consecutive patients using nocturnal NPPV at home were enrolled during their routine follow up if 1) they were in a stable condition, with no respiratory exacerbation during the previous two months, 2) they were using NPPV for at least one month, and 3) they had no clinical symptoms of nocturnal hypoventilation such as frequent arousals, nocturnal agitation, or daytime fatigue and sleepiness. Exclusion criteria were 1) age less than one year because the ear clip of the $\mathrm{PtcCO}_{2} / \mathrm{SpO}_{2}$ monitor is too large for small infants ${ }^{3}$, 2) ear aplasia or hypoplasia for the same technical reasons ${ }^{3}, 3$ ) dark skin because of inaccurate $\mathrm{SpO}_{2}$ values, as has been observed with other devices $\left.{ }^{4}, 4\right)$ impossibility to perform the hospital and home recording within one month, and 5) any change in the respiratory and/or clinical status of the patient. 
All the parents, and if possible the patients, gave informed written consent for the study which was approved by the local ethical committee.

\section{Overnight $\mathrm{PtcCO}_{2} / \mathrm{SpO}_{2}$ recording}

Two overnight $\mathrm{PtcCO} / \mathrm{SpO}_{2}$ recordings were performed in a random order with the SenTec Digital Monitor (software version SMB SW-V06.10; MPB SWV04.03) and the V-SignTM Sensor which was applied to the earlobe with a dedicated Ear Clip (SenTec AG, Therwil, Switzerland). This fully digital sensor combines the elements of an electrochemical Severinghaus-type $\mathrm{CO}_{2}$ tension sensor with the optical elements of conventional $\mathrm{SpO}_{2}$ sensors, thus providing a noninvasive and continuous $\mathrm{PtcCO}_{2}$ and $\mathrm{SpO}_{2}$ monitoring. The sensor is warmed to a constant surface temperature of $42^{\circ} \mathrm{C}$ to improve local arterialization of the measurement site. This $\mathrm{PtcCO}_{2} / \mathrm{SpO}_{2}$ monitor has been validated for adults ${ }^{5}$ and for children in our laboratory ${ }^{3}$.

The two overnight $\mathrm{SpO}_{2}$ and $\mathrm{PtcCO}_{2}$ recordings were started at the patient's usual bedtime. In the hospital, care was taken to respect the patient's sleep. Prior to the application of the sensor to the patient, the sensor was prepared by the nurse in the hospital and the technician at home and calibrated as per the manufacturer recommendations. The sensor was then applied by the nurse or the technician to the patient's earlobe for 15 minutes, until the stabilization of the $\mathrm{PtcCO}_{2}$ and $\mathrm{SpO}_{2}$ values. Monitoring was then performed during at least 6 hours. In the hospital, sleep with NPPV as well as the correct positioning of the nasal mask and the ear clip was regularly checked by the attending nurse during the night. At home, the parents were asked to check these elements before they went to sleep and eventually a second 
time during the night. The parents were taught how to remove the ear clip at awakening.

After the two recordings, the parents were asked: "Did your child sleep better in the hospital or at home ?" and "Do you prefer a recording performed in the hospital or at home ?".

Analysis of the nocturnal gas exchange

For each overnight sleep study, the following data were calculated: duration of recording, mean and minimal $\mathrm{SpO}_{2}$, percentage of night time spent with a $\mathrm{SpO}_{2}>$ 95\%, between 94 and 95\%, between 93 and 92\%, and < 92\%; mean and maximal $\mathrm{PtcCO}_{2}, \%$ of night time spent with a $\mathrm{PtcCO}_{2}>50 \mathrm{~mm} \mathrm{Hg}$ and $\leq 50 \mathrm{mmHg}$.

Statistical analysis

The patients were separated into two groups; patients with neuromuscular diseases $(n=11)$ and patients with other disorders $(n=13)$. For each group and type of recording (hospital and home), the median value of mean and minimal $\mathrm{SpO}_{2}$ and of mean and maximal $\mathrm{PtcCO}_{2}$ was calculated because the values were not normally distributed. Comparison between the home and hospital recordings was performed by the Mann Whitney Rank Sum test.

Moreover, individual data were analyzed by plotting mean and minimal $\mathrm{SpO}_{2}$ and mean and maximal $\mathrm{PtcCO}_{2}$ observed in the hospital against the values obtained at home for each patient. Correlation between the values recorded at home and in the hospital was performed using simple linear regression. Statistical analyses were 
done using the SigmaStat (Systat Software Inc., San Jose, California). Values of $\mathrm{p}<0.05$ were considered statistically significant.

\section{Results}

Patients

Twenty four consecutive patients were included in the study with 5 patients having 2 series of hospital and home recording more than 3 months apart. Four patients with neuromuscular disease and one patient with another disorder had 2 pairs of recordings. The characteristics of the patients are given in Table 1.

\section{Feasibility of home recording}

Of the 29 recordings performed at home, one recording was technically correct but could not be analyzed because of an error on the date. The $\mathrm{SpO}_{2}$ recording could not be analyzed in another patient in the hospital but the $\mathrm{PtcCO}_{2}$ recording was exploitable. All the other recordings performed at home and in the hospital were correct and could be analyzed.

Comparison of home and hospital recordings

Despite randomization, only 4 recordings were initially performed at home and 25 in the hospital. The median delay between the hospital and home recordings was 11 (range 3-28) days in patients with neuromuscular disease and 7 (2-30) days in 
patients with other disorders ( $p$ not significant (NS)). The median duration of the overnight $\mathrm{PtcCO}_{2} / \mathrm{SpO}_{2}$ recording was comparable at home (503 minutes, range 360609 ) and in the hospital (560 minutes, range $231-688, p=N S$ ). Table 2 shows that the $\mathrm{SpO}_{2}$ and $\mathrm{PtcCO}_{2}$ values did not differ significantly between the hospital and the home. Moreover, the results were not different between the patients with neuromuscular disease and those with other disorders. Figure 1 shows the correlation of mean and minimal $\mathrm{SpO}_{2}$ values in the hospital and at home for each patient. The correlation of mean $\mathrm{SpO}_{2}$ in the hospital and at home was significant for patients with other disorders $(r=0.608, p=0.028)$ but not for patients with neuromuscular diseases $(r=0.494, \mathrm{p}=0.061)$. For minimal $\mathrm{SpO}_{2}$, no significant correlation was observed for the two groups of patients $(r=0.340, p=0.215$ and $r=0.547, p=0.053$ for patients with neuromuscular disease and other diseases, respectively). Interestingly, 4 patients had a minimal $\mathrm{SpO}_{2}$ below $90 \%$ in the hospital but not at home, and conversely, 9 patients had a minimal $\mathrm{SpO}_{2}$ below $90 \%$ at home but not in the hospital. Figure 2 shows the percentage of time spent with the different $\mathrm{SpO}_{2}$ ranges in the two groups of patients. Again, no significant differences were observed between the recordings performed in the hospital and at home in both groups of patients (t-test, all NS).

Figure 3 shows the correlation of mean and maximal $\mathrm{PtcCO}_{2}$ values in the hospital and at home for each patient. The correlation of mean $\mathrm{PtcCO}_{2}$ in the hospital and at home was significant in the two groups of patients $(r=0.647, p=0.009$, and $r=0.562, p=0.037$, for patients with neuromuscular disease and patients with other disorders, respectively). The correlation for maximal $\mathrm{PtcCO}_{2}$ was significant for patients with other diseases $(r=0.636, p=0.014)$ but not for patients with neuromuscular diseases $(r=0.417, p=0.122)$. Figure 4 shows the percentage of time 
spent with the different $\mathrm{PtcCO}_{2}$ ranges in the two groups of patients. Again, no significant differences were observed between the recordings performed in the hospital and at home in both groups of patients (t-test, all NS).

According to the parents, they all found that their child slept better at home. With regard to the satisfaction of the parents, they all preferred the recording at home.

The cost of one overnight hospitalization in our pediatric pulmonology unit is 1029,00 euros. This cost should be compared to 2 technician home visits, one in the evening at the child's bedtime and one in the morning $(2 \times 25,16=50,32$ euros $)$. The cost of the transport has to be added to this amount; the French health care system reimburses 20,09 euros per visit, which make a total of 90,50 euros per home monitoring.

The 5 patients who had persistent alveolar hypoventilation during both recordings, as defined by a maximal $\mathrm{PtcCO}_{2}$ value $>50 \mathrm{~mm} \mathrm{Hg}$ and/or a minimal $\mathrm{SpO}_{2}$ value $<90 \%$ had one or several interventions in the hospital such as the change of the ventilatory settings or mode, the addition of an abdominal girdle or a chin strap, and/or the change of the interface. An overnight gas exchange control was performed systematically before discharge.

\section{Discussion}

This study is the first to show the feasibility of overnight $\mathrm{PtcCO}_{2} / \mathrm{SpO}_{2}$ recording in a group of children over the age of 4 years, treated at home with long term NPPV. Twenty eight of the 29 (97\%) recordings were analyzable when a trained technician installed the equipment at home and instructed the parents how to 
supervise the recording and remove the ear clip in the morning. $\mathrm{SpO}_{2}$ and $\mathrm{PtcCO}_{2}$ values did not differ significantly between the hospital and the home. However, a better correlation between hospital and home values was observed for mean values as compared to minimal and maximal values, and in patients with other disorders as compared to patients with neuromuscular disease. Of note, parent's preference and cost favored home recording.

Different types of monitoring are routinely performed at home in children such as cardiorespiratory monitoring in children at risk for sudden infant death syndrome ${ }^{6-}$ ${ }^{8}, \mathrm{pH}$ monitoring for the diagnosis of gastro-oesophageal reflux ${ }^{9}$, blood pressure monitoring ${ }^{10}$, EEG monitoring ${ }^{11,12}$, polygraphy for the screening of obstructive sleep apnea ${ }^{13-16}$, and even telemonitoring of exhaled nitric oxide for asthmatic children ${ }^{17}$.

We were initially relatively reluctant to the use of the $\mathrm{PtcCO} / \mathrm{SpO}_{2}$ monitor at home because the device requires a correct calibration, the SignTM Sensor is quite fragile, and the correct positioning of the ear clip with the head gear for the NPPV may not be easy in a young child. Technically acceptable recordings were obtained in $75 \%$ to $99 \%$ of the cases during the above mentioned studies ${ }^{6-17}$. However, no technical problem occurred at home during any of the 29 recordings in the present study. This may be explained by the adequate training of the technicians of the home care organization who installed the $\mathrm{PtcCO} / \mathrm{SpO}_{2}$ monitor on the child at bed time, which requires thus a home visit outside office hours. However, this procedure seemed for us the guarantee of success.

Correlation between hospital and home recordings was better for mean $\mathrm{SpO}_{2}$ and $\mathrm{PtcCO}_{2}$ values than for minimal $\mathrm{SpO}_{2}$ and maximal $\mathrm{PtcCO}_{2}$. This is easy understandable because a mean value is calculated over the whole recording period, and it thus less variable than an extreme value. We have no clear explanation for the 
better correlation between hospital and home $\mathrm{SpO}_{2}$ and $\mathrm{PtcCO}_{2}$ values in patients with other diseases as compared to patients with neuromuscular diseases. A possible explanation could be that patients with other diseases, who are predominantly patients with upper airway obstruction, are more stable than patients with neuromuscular disease. In practice, minimal and maximal values should be interpreted with more caution than mean values when comparing hospital and home recordings.

A limitation of our study is the lack of data on objective sleep quality. Improved nocturnal gas exchange is not obligatory associated with better sleep quality ${ }^{18}$. A parallel improvement in nocturnal gas exchange and sleep architecture during NPPV has been observed in adult patients in two studies ${ }^{19,20}$ but not in two others ${ }^{21,22}$. A study establishing home polysomnography norms for children showed better sleep quantity and quality at home ${ }^{14}$. Another study compared 2 sleep studies performed at home and in the hospital in 21 children aged 2-12 years with possible obstructive sleep apnea ${ }^{13}$. Sleep efficiency was significantly greater and the arousal index was significantly lower at home than in the laboratory. Finally, a study that compared blood pressure monitoring at home and in the hospital also observed significant lower diastolic blood pressure at home ${ }^{10}$, which supports a lower stress level when children are in their home environment.

Even if we observed a trend for better results during home recordings, this was not significant (Table 2). We may thus conclude that home recordings are feasible and may show results comparable to those obtained at hospital, justifying their integration in the routine management in children receiving long term NPPV. A regular and systematic check of the ventilator settings and circuit, the interface and its possible side effects, and also the potential problems that may occur during NPPV 
such as air leaks, are, to our opinion, important to document during an overnight observation in the hospital. As such, we would recommend a combination of home and hospital recordings, nor only for the patient's and parent's comfort but also with regard to the familial and financial burden. Because individual data may be better in the home or in the hospital, we would recommend a change of NPPV settings or additional measures only in case of abnormal values in both conditions. Those patients with an abnormal "in home" gas exchange should be referred for an "in hospital" titration study.

In conclusion, overnight $\mathrm{PtcCO} / \mathrm{SpO}_{2}$ monitoring is feasible at home and shows comparable results to hospital recordings. Systematic and regular home monitoring, combined with regular hospital visits, is recommended in children treated at home with NPPV.

\section{Acknowledgments}

All the authors declare that they have no conflict of interest with the data presented in this manuscript. 


\section{References}

1. Fauroux B, Sardet A, Foret D. Home treatment for chronic respiratory failure in children: a prospective study. Eur Resp J 1995;8:2062-2066.

2. Fauroux B, Boffa C, Desguerre I, Estournet B, Trang H. Long-term noninvasive mechanical ventilation for children at home: A national survey. Pediatr Pulmonol 2003;35:119-125.

3. Paiva R, Krivec U, Aubertin G, Cohen E, Clément A, Fauroux B. Carbon dioxide monitoring during long-term noninvasive respiratory support in children. Intensive Care Med 2009;35:1068-1074.

4. Feiner JR, Severinghaus JW, Bickler PE. Dark skin decreases the accuracy of pulse oximeters at low oxygen saturation: the effects of oximeter probe type and gender. Anesth Analg 2007;105(6 Suppl):S18-23.

5. Domingo $C$, Canturri $E$, Luján $M$, Moreno $A$, Espuelas $H$, Marín $A$. Transcutaneous measurement of partial pressure of carbon dioxide and oxygen saturation: validation of the SenTec monitor. Arch Bronconeumol 2006;42:246-251.

6. Cornwell AC, Weitzman ED, Marmarou A. Ambulatory and in-hospital continuous recording of sleep state and cardiorespiratory parameters in 'near miss' for the sudden infant death syndrome and control infants. Biotelem Patient Monit 1978;5:113-122.

7. Johnson P. The clinical and economic advantages of remote, communitybased physiological assessment. J Telemed Telecare 1998;4 Suppl 1:64-66.

8. Poels PJ, Schilder AG, van den Berg S, Hoes AW, F JK. Evaluation of a new device for home cardiorespiratory recording in children. Arch Otolaryngol Head Neck Surg 2003;129:1281-1284. 
9. Falor WH, Miller J, Kraus J, Fannin S, Greczanik V, Crocker N, Taylor B. Twenty-four-hour monitoring of esophagopharyngeal $\mathrm{pH}$ in outpatients. Use of four-channel pH probe and computerized system. J Thorac Cardiovasc Surg $1986 ; 91: 16-22$.

10. Furusawa EA, Filho UD, Koch VH. Home blood pressure monitoring in paediatric chronic hypertension. J Hum Hypertens 2009;23:464-469.

11. Beun AM, Gutter T, Overweg J. Home EEG and video monitoring in epilepsy: first experiences. Clin Neurol Neurosurg 1994;96:257-260.

12. Manni R, Galimberti CA, Sartori I, Politini L, Murelli R, Tartara A. Nocturnal partial seizures and arousals/awakenings from sleep: an ambulatory EEG study. Funct Neurol 1997;12:107-111.

13. Jacob SV, Morielli A, Mograss MA, Ducharme FM, Schloss MD, T BR. Home testing for pediatric obstructive sleep apnea syndrome secondary to adenotonsillar hypertrophy. Pediatr Pulmonol 1995;20:241-252.

14. Stores G, Crawford C, Selman J, Wiggs L. Home polysomnography norms for children. Technol Health Care 1998;6:231-236.

15. Acebo C, Sadeh A, Seifer R, Tzischinsky O, Wolfson AR, Hafer A, Carskadon MA. Estimating sleep patterns with activity monitoring in children and adolescents: how many nights are necessary for reliable measures? Sleep 1999;22:95-103.

16. Quan SF, Goodwin JL, Babar SI, Kaemingk KL, Enright PL, Rosen GM, Fregosi RF, Morgan WJ. Sleep architecture in normal Caucasian and Hispanic children aged 6-11 years recorded during unattended home polysomnography: experience from the Tucson Children's Assessment of Sleep Apnea Study (TuCASA). Sleep Med 2003;4:13-19. 
17. de Jongste JC, Carraro S, Hop WC, CHARISM Study Group, Baraldi E. Daily telemonitoring of exhaled nitric oxide and symptoms in the treatment of childhood asthma. Am J Respir Crit Care Med 2009;179:93-97.

18. Midgren B. Assisted ventilation during sleep: improving respiration or sleep or both? Respir Med 2009;103:163-164.

19. Fanfulla F, Delmastro M, Berardinelli A, Lupo ND, Nava S. Effects of different ventilator settings on sleep and inspiratory effort in patients with neuromuscular disease. Am J Respir Crit Care Med 2005;172:619-624.

20. Orlikowski D, Mroue G, Prigent H, Moulin C, Bohic M, Ruquet M, Raphael JC, Annane D, Lofaso F. Automatic air-leak compensation in neuromuscular patients: a feasibility study. Respir Med 2009;103:173-179.

21. Teschler H, Stampa J, Ragette R, Konietzko N, Berthon-Jones M. Effect of mouth leak on effectiveness of nasal bilevel ventilatory assistance and sleep architecture. Eur Respir J 1999;14:1251-1257.

22. Borel JC, Sabil A, Janssens JP, Couteau M, Boulon L, Lévy P, Pépin JL. Intentional leaks in industrial masks have a significant impact on efficacy of bilevel noninvasive ventilation: a bench test study. Chest 2009;135:669-677. 


\section{Legend of the figures}

\section{Figure 1}

Individual mean (left figure) and minimal (right figure) pulse oximetry $\left(\mathrm{SpO}_{2}\right)$ values observed at home and in the hospital in patients with neuromuscular disease (black circles) and with other disorders (open circles).

For mean $\mathrm{SpO}_{2}$, regression lines are represented (plain for patients with neuromuscular disease $(r=0.494, p=0.061)$ and dashed for patients with other disorders $(r=0.608, p=0.028))$. Several patients having similar $\mathrm{SpO}_{2}$ values, only 15 of the 28 spots are visible.

For minimal $\mathrm{SpO}_{2}$, regression lines are represented (plain for patients with neuromuscular disease $(r=0.340, p=N S)$ and dashed for patients with other disorders $(r=0.547, p=N S)$. Two patients having similar $\mathrm{SpO}_{2}$ values, only 27 of the 28 spots are visible.

\section{Figure 2}

Comparison of percentage of nocturnal recording time spent with a pulse oximetry $\left(\mathrm{SpO}_{2}\right)>95 \%$, between 94 and 95\%, between 93 and $92 \%$, and < $92 \%$ during the recordings performed in the hospital (black bars) and at home (grey bars).

\section{Figure 3}

Individual mean (left figure) and maximal (right figure) transcutaneous carbon dioxide $\left(\mathrm{PtcCO}_{2}\right)$ values observed at home and in the hospital in patients with neuromuscular disease (black circles) and with other disorders (open circles). 
For mean $\mathrm{PtcCO}_{2}$, regression lines are represented (plain for patients with neuromuscular disease $(r=0.647, p=0.009)$ and dashed for patients with other disorders $(r=0.564, p=0.037))$

For maximal $\mathrm{PtcCO}_{2}$, regression lines are represented (plain for patients with neuromuscular disease $(r=0.417, p=N S)$ and dashed for patients with other disorders $(r=0.636, p=0.014)$.

Three patients having similar $\mathrm{PtcCO}_{2}$ values, only 27 of the 29 spots are visible.

\section{Figure 4}

Comparison of percentage of nocturnal recording time spent with a $\mathrm{PtcCO}_{2}>50$ $\mathrm{mmHg}$ and $\leq 50 \mathrm{mmHg}$ during the recordings performed in the hospital (black bars) and at home (grey bars). 


\section{Value of gas exchange recording at home in children receiving noninvasive ventilation}

Osama Felemban ${ }^{1,2}$, MD, Karl Leroux ${ }^{3}$, AAS, Guillaume Aubertin², MD, Fabrice Miandy ${ }^{3}$, AAS, Frédéric Damagnez ${ }^{3}$, AAS, Bruno Amorim ${ }^{3}$, AAS, Adriana Ramirez ${ }^{2}$, AAS, Brigitte Fauroux ${ }^{2,4}, M D, P h D$

${ }^{1}$ University Hospital, Faculty of Medicine, King Abdulaziz University, Jeddah 21589, Kingdom of Saudi Arabia

${ }^{2}$ AP-HP, Hôpital Armand Trousseau, Pediatric Pulmonary Department, Paris, France ${ }^{3}$ ADEP Assistance, Suresnes, Paris, France

${ }^{4}$ Université Pierre et Marie Curie-Paris 6 and INSERM UMR S-938, Paris, France

Correspondence to:

Pr. Brigitte Fauroux, MD, PhD

AP-HP, Hôpital Armand-Trousseau

Pediatric Pulmonary Department

Research unit INSERM UMR S-938

National reference center for rare lung diseases

Université Pierre et Marie Curie-Paris 6

26 avenue du Docteur Arnold-Netter

Paris, F-75012 France

Fax: +33 (0) 144736174

Tel: +33 (0) 144736718

Email: brigitte.fauroux@trs.aphp.fr

\section{Supports and grants}

The research of Brigitte Fauroux is supported by the Association Française contre les Myopathies (AFM), Assistance Publique-Hôpitaux de Paris, Inserm, ADEP Assistance, and Université Pierre et Marie Curie-Paris 6.

Running head: Gas exchange during noninvasive ventilation

Word count of the body of the manuscript: 2511 


\begin{abstract}
Noninvasive positive pressure ventilation (NPPV) is preferentially performed at home. The objectives of the study were to evaluate the feasibility of an overnight gas exchange recording at home and to compare recordings performed in the hospital and at home.
\end{abstract}

Twenty nine pairs of overnight gas exchange recordings during NPPV were performed at home and in the hospital in 11 children with neuromuscular disease and 13 children with other disorders treated with long term NPPV.

No technical problem occurred during the recordings performed at home and one pulse oximetry $\left(\mathrm{SpO}_{2}\right)$ recording failed in the hospital. For the two groups, $\mathrm{SpO}_{2}$ and transcutaneous carbon dioxide $\left(\mathrm{PtcCO}_{2}\right)$ values did not differ significantly between the hospital and the home. However, correlations between $\mathrm{SpO}_{2}$ and $\mathrm{PtcCO}_{2}$ values obtained in the hospital and at home were better for mean values than for minimal and maximal values, and in patients with other disorders as compared to patients with neuromuscular disease.

Overnight gas exchange recordings with NPPV by a combined $\mathrm{PtcCO} / \mathrm{SpO}_{2}$ monitor are feasible at home and show results comparable to hospital recordings. Home $\mathrm{PtcCO}_{2} / \mathrm{SpO}_{2}$ recordings may be integrated in the care of children treated with domiciliary NPPV and are associated with less disruption of family life and decreased health care costs.

Word count of the abstract: 204

Key words: carbon dioxide, child, gas exchange, home, noninvasive positive pressure ventilation, pulse oximetry. 


\section{Introduction}

Noninvasive positive pressure ventilation (NPPV) is increasingly used in children presenting various diseases which may cause alveolar hypoventilation such as neuromuscular or lung disease, thoracic deformities, severe upper airway obstruction, or disorders of ventilatory control ${ }^{1,2}$. The main advantage of NPPV is that this technique may be used on demand, preferentially at night, with minimal disruption of normal life. After appropriate training of the family and caregivers, the majority of the children may be discharged home. Regular clinical and physiological follow up is necessary in order to adapt the NPPV modes and settings to the patient's clinical status and growth, and to check any side effect or respiratory or maxillofacial complication.

We have recently demonstrated the importance of a systematic overnight combined pulse oximetry $\left(\mathrm{SpO}_{2}\right)$ and carbon dioxide $\left(\mathrm{CO}_{2}\right)$ recording, even in patients in a stable condition without any symptom or sign of alveolar hypoventilation ${ }^{3}$. Indeed, $42 \%$ of 50 children who were well acclimatized to NPPV, without evidence of symptoms of sleep disordered breathing, were hypercapnic, defined by a maximal transcutaneous $\mathrm{CO}_{2}\left(\mathrm{PtcCO}_{2}\right)$ value $>50 \mathrm{mmHg}$ during sleep. Most importantly, this nocturnal hypercapnia was not associated with nocturnal hypoxemia, defined by a minimal $\mathrm{SpO}_{2}<92 \%$, or abnormal daytime blood gases in $36 \%$ of the patients.

Repeated overnight hospitalizations are associated with disruption of family life and increased health care costs. Because of a general reduction in number of pediatric hospital beds, the transfer of selected, programmed, and well-organized activities or investigations from the hospital to the home is strongly encouraged. However, the feasibility, defined by the ability to obtain technically acceptable 
overnight recordings as well as the satisfaction of the parents with regard to their preference between hospital and home, and accuracy of these investigations performed in a home environment, should be evaluated before their wide spread use.

The aim of the present study was first to evaluate the feasibility of an overnight gas exchange recording by a combined transcutaneous $\mathrm{CO}_{2}$ and pulse oximetry $\left(\mathrm{PtcCO}_{2} / \mathrm{SpO}_{2}\right)$ monitor at home, and second to compare the results and costs of recordings performed in the hospital and at home in a cohort of stable children, treated at home with long term NPPV.

\section{Material and methods}

Patients

Consecutive patients using nocturnal NPPV at home were enrolled during their routine follow up if 1) they were in a stable condition, with no respiratory exacerbation during the previous two months, 2) they were using NPPV for at least one month, and 3) they had no clinical symptoms of nocturnal hypoventilation such as frequent arousals, nocturnal agitation, or daytime fatigue and sleepiness. Exclusion criteria were 1) age less than one year because the ear clip of the $\mathrm{PtcCO}_{2} / \mathrm{SpO}_{2}$ monitor is too large for small infants ${ }^{3}$, 2) ear aplasia or hypoplasia for the same technical reasons ${ }^{3}, 3$ ) dark skin because of inaccurate $\mathrm{SpO}_{2}$ values, as has been observed with other devices $\left.{ }^{4}, 4\right)$ impossibility to perform the hospital and home recording within one month, and 5) any change in the respiratory and/or clinical status of the patient. 
All the parents, and if possible the patients, gave informed written consent for the study which was approved by the local ethical committee.

\section{Overnight $\mathrm{PtcCO}_{2} / \mathrm{SpO}_{2}$ recording}

Two overnight $\mathrm{PtcCO} / \mathrm{SpO}_{2}$ recordings were performed in a random order with the SenTec Digital Monitor (software version SMB SW-V06.10; MPB SWV04.03) and the V-SignTM Sensor which was applied to the earlobe with a dedicated Ear Clip (SenTec AG, Therwil, Switzerland). This fully digital sensor combines the elements of an electrochemical Severinghaus-type $\mathrm{CO}_{2}$ tension sensor with the optical elements of conventional $\mathrm{SpO}_{2}$ sensors, thus providing a noninvasive and continuous $\mathrm{PtcCO}_{2}$ and $\mathrm{SpO}_{2}$ monitoring. The sensor is warmed to a constant surface temperature of $42^{\circ} \mathrm{C}$ to improve local arterialization of the measurement site. This $\mathrm{PtcCO}_{2} / \mathrm{SpO}_{2}$ monitor has been validated for adults ${ }^{5}$ and for children in our laboratory ${ }^{3}$.

The two overnight $\mathrm{SpO}_{2}$ and $\mathrm{PtcCO}_{2}$ recordings were started at the patient's usual bedtime. In the hospital, care was taken to respect the patient's sleep. Prior to the application of the sensor to the patient, the sensor was prepared by the nurse in the hospital and the technician at home and calibrated as per the manufacturer recommendations. The sensor was then applied by the nurse or the technician to the patient's earlobe for 15 minutes, until the stabilization of the $\mathrm{PtcCO}_{2}$ and $\mathrm{SpO}_{2}$ values. Monitoring was then performed during at least 6 hours. In the hospital, sleep with NPPV as well as the correct positioning of the nasal mask and the ear clip was regularly checked by the attending nurse during the night. At home, the parents were asked to check these elements before they went to sleep and eventually a second 
time during the night. The parents were taught how to remove the ear clip at awakening.

After the two recordings, the parents were asked: "Did your child sleep better in the hospital or at home ?" and "Do you prefer a recording performed in the hospital or at home?".

\section{Analysis of the nocturnal gas exchange}

For each overnight sleep study, the following data were calculated: duration of recording, mean and minimal $\mathrm{SpO}_{2}$, percentage of night time spent with a $\mathrm{SpO}_{2}>$ 95\%, between 94 and 95\%, between 93 and $92 \%$, and < $92 \%$; mean and maximal $\mathrm{PtcCO}_{2}, \%$ of night time spent with a $\mathrm{PtcCO}_{2}>50 \mathrm{~mm} \mathrm{Hg}$ and $\leq 50 \mathrm{mmHg}$.

Statistical analysis

The patients were separated into two groups; patients with neuromuscular diseases $(n=11)$ and patients with other disorders $(n=13)$. For each group and type of recording (hospital and home), the median value of mean and minimal $\mathrm{SpO}_{2}$ and of mean and maximal $\mathrm{PtcCO}_{2}$ was calculated because the values were not normally distributed. Comparison between the home and hospital recordings was performed by the Mann Whitney Rank Sum test.

Moreover, individual data were analyzed by plotting mean and minimal $\mathrm{SpO}_{2}$ and mean and maximal $\mathrm{PtcCO}_{2}$ observed in the hospital against the values obtained at home for each patient. Correlation between the values recorded at home and in the hospital was performed using simple linear regression. Statistical analyses were 
done using the SigmaStat (Systat Software Inc., San Jose, California). Values of $\mathrm{p}<0.05$ were considered statistically significant.

\section{Results}

Patients

Twenty four consecutive patients were included in the study with 5 patients having 2 series of hospital and home recording more than 3 months apart. Four patients with neuromuscular disease and one patient with another disorder had 2 pairs of recordings. The characteristics of the patients are given in Table 1.

\section{Feasibility of home recording}

Of the 29 recordings performed at home, one recording was technically correct but could not be analyzed because of an error on the date. The $\mathrm{SpO}_{2}$ recording could not be analyzed in another patient in the hospital but the $\mathrm{PtcCO}_{2}$ recording was exploitable. All the other recordings performed at home and in the hospital were correct and could be analyzed.

Comparison of home and hospital recordings

Despite randomization, only 4 recordings were initially performed at home and 25 in the hospital. The median delay between the hospital and home recordings was 11 (range 3-28) days in patients with neuromuscular disease and 7 (2-30) days in 
patients with other disorders ( $p$ not significant (NS)). The median duration of the overnight $\mathrm{PtcCO}_{2} / \mathrm{SpO}_{2}$ recording was comparable at home (503 minutes, range 360609 ) and in the hospital (560 minutes, range 231-688, $p=N S$ ). Table 2 shows that the $\mathrm{SpO}_{2}$ and $\mathrm{PtcCO}_{2}$ values did not differ significantly between the hospital and the home. Moreover, the results were not different between the patients with neuromuscular disease and those with other disorders. Figure 1 shows the correlation of mean and minimal $\mathrm{SpO}_{2}$ values in the hospital and at home for each patient. The correlation of mean $\mathrm{SpO}_{2}$ in the hospital and at home was significant for patients with other disorders $(r=0.608, p=0.028)$ but not for patients with neuromuscular diseases $(r=0.494, p=0.061)$. For minimal $\mathrm{SpO}_{2}$, no significant correlation was observed for the two groups of patients $(r=0.340, p=0.215$ and $r=0.547, p=0.053$ for patients with neuromuscular disease and other diseases, respectively). Interestingly, 4 patients had a minimal $\mathrm{SpO}_{2}$ below $90 \%$ in the hospital but not at home, and conversely, 9 patients had a minimal $\mathrm{SpO}_{2}$ below $90 \%$ at home but not in the hospital. Figure 2 shows the percentage of time spent with the different $\mathrm{SpO}_{2}$ ranges in the two groups of patients. Again, no significant differences were observed between the recordings performed in the hospital and at home in both groups of patients (t-test, all NS).

Figure 3 shows the correlation of mean and maximal $\mathrm{PtcCO}_{2}$ values in the hospital and at home for each patient. The correlation of mean $\mathrm{PtcCO}_{2}$ in the hospital and at home was significant in the two groups of patients $(r=0.647, p=0.009$, and $r=0.562, p=0.037$, for patients with neuromuscular disease and patients with other disorders, respectively). The correlation for maximal $\mathrm{PtcCO}_{2}$ was significant for patients with other diseases $(r=0.636, p=0.014)$ but not for patients with neuromuscular diseases $(r=0.417, p=0.122)$. Figure 4 shows the percentage of time 
spent with the different $\mathrm{PtcCO}_{2}$ ranges in the two groups of patients. Again, no significant differences were observed between the recordings performed in the hospital and at home in both groups of patients (t-test, all NS).

According to the parents, they all found that their child slept better at home. With regard to the satisfaction of the parents, they all preferred the recording at home.

The cost of one overnight hospitalization in our pediatric pulmonology unit is 1029,00 euros. This cost should be compared to 2 technician home visits, one in the evening at the child's bedtime and one in the morning $(2 \times 25,16=50,32$ euros $)$. The cost of the transport has to be added to this amount; the French health care system reimburses 20,09 euros per visit, which make a total of 90,50 euros per home monitoring.

The 5 patients who had persistent alveolar hypoventilation during both recordings, as defined by a maximal $\mathrm{PtcCO}_{2}$ value $>50 \mathrm{~mm} \mathrm{Hg}$ and/or a minimal $\mathrm{SpO}_{2}$ value $<90 \%$ had one or several interventions in the hospital such as the change of the ventilatory settings or mode, the addition of an abdominal girdle or a chin strap, and/or the change of the interface. An overnight gas exchange control was performed systematically before discharge.

\section{Discussion}

This study is the first to show the feasibility of overnight $\mathrm{PtcCO}_{2} / \mathrm{SpO}_{2}$ recording in a group of children over the age of 4 years, treated at home with long term NPPV. Twenty eight of the 29 (97\%) recordings were analyzable when a trained technician installed the equipment at home and instructed the parents how to 
supervise the recording and remove the ear clip in the morning. $\mathrm{SpO}_{2}$ and $\mathrm{PtcCO}_{2}$ values did not differ significantly between the hospital and the home. However, a better correlation between hospital and home values was observed for mean values as compared to minimal and maximal values, and in patients with other disorders as compared to patients with neuromuscular disease. Of note, parent's preference and cost favored home recording.

Different types of monitoring are routinely performed at home in children such as cardiorespiratory monitoring in children at risk for sudden infant death syndrome ${ }^{6-}$ ${ }^{8}, \mathrm{pH}$ monitoring for the diagnosis of gastro-oesophageal reflux ${ }^{9}$, blood pressure monitoring ${ }^{10}$, EEG monitoring ${ }^{11,12}$, polygraphy for the screening of obstructive sleep apnea ${ }^{13-16}$, and even telemonitoring of exhaled nitric oxide for asthmatic children ${ }^{17}$.

We were initially relatively reluctant to the use of the $\mathrm{PtcCO}_{2} / \mathrm{SpO}_{2}$ monitor at home because the device requires a correct calibration, the SignTM Sensor is quite fragile, and the correct positioning of the ear clip with the head gear for the NPPV may not be easy in a young child. Technically acceptable recordings were obtained in $75 \%$ to $99 \%$ of the cases during the above mentioned studies ${ }^{6-17}$. However, no technical problem occurred at home during any of the 29 recordings in the present study. This may be explained by the adequate training of the technicians of the home care organization who installed the $\mathrm{PtcCO} / \mathrm{SpO}_{2}$ monitor on the child at bed time, which requires thus a home visit outside office hours. However, this procedure seemed for us the guarantee of success.

Correlation between hospital and home recordings was better for mean $\mathrm{SpO}_{2}$ and $\mathrm{PtcCO}_{2}$ values than for minimal $\mathrm{SpO}_{2}$ and maximal $\mathrm{PtcCO}_{2}$. This is easy understandable because a mean value is calculated over the whole recording period, and it thus less variable than an extreme value. We have no clear explanation for the 
better correlation between hospital and home $\mathrm{SpO}_{2}$ and $\mathrm{PtcCO}_{2}$ values in patients with other diseases as compared to patients with neuromuscular diseases. A possible explanation could be that patients with other diseases, who are predominantly patients with upper airway obstruction, are more stable than patients with neuromuscular disease. In practice, minimal and maximal values should be interpreted with more caution than mean values when comparing hospital and home recordings.

A limitation of our study is the lack of data on objective sleep quality. Improved nocturnal gas exchange is not obligatory associated with better sleep quality ${ }^{18}$. A parallel improvement in nocturnal gas exchange and sleep architecture during NPPV has been observed in adult patients in two studies ${ }^{19,20}$ but not in two others ${ }^{21,22}$. A study establishing home polysomnography norms for children showed better sleep quantity and quality at home ${ }^{14}$. Another study compared 2 sleep studies performed at home and in the hospital in 21 children aged 2-12 years with possible obstructive sleep apnea ${ }^{13}$. Sleep efficiency was significantly greater and the arousal index was significantly lower at home than in the laboratory. Finally, a study that compared blood pressure monitoring at home and in the hospital also observed significant lower diastolic blood pressure at home ${ }^{10}$, which supports a lower stress level when children are in their home environment.

Even if we observed a trend for better results during home recordings, this was not significant (Table 2). We may thus conclude that home recordings are feasible and may show results comparable to those obtained at hospital, justifying their integration in the routine management in children receiving long term NPPV. A regular and systematic check of the ventilator settings and circuit, the interface and its possible side effects, and also the potential problems that may occur during NPPV 
such as air leaks, are, to our opinion, important to document during an overnight observation in the hospital. As such, we would recommend a combination of home and hospital recordings, nor only for the patient's and parent's comfort but also with regard to the familial and financial burden. Because individual data may be better in the home or in the hospital, we would recommend a change of NPPV settings or additional measures only in case of abnormal values in both conditions. Those patients with an abnormal "in home" gas exchange should be referred for an "in hospital" titration study.

In conclusion, overnight $\mathrm{PtcCO}_{2} / \mathrm{SpO}_{2}$ monitoring is feasible at home and shows comparable results to hospital recordings. Systematic and regular home monitoring, combined with regular hospital visits, is recommended in children treated at home with NPPV.

\section{Acknowledgments}

All the authors declare that they have no conflict of interest with the data presented in this manuscript. 


\section{References}

1. Fauroux B, Sardet A, Foret D. Home treatment for chronic respiratory failure in children: a prospective study. Eur Resp J 1995;8:2062-2066.

2. Fauroux B, Boffa C, Desguerre I, Estournet B, Trang H. Long-term noninvasive mechanical ventilation for children at home: A national survey. Pediatr Pulmonol 2003;35:119-125.

3. Paiva R, Krivec U, Aubertin G, Cohen E, Clément A, Fauroux B. Carbon dioxide monitoring during long-term noninvasive respiratory support in children. Intensive Care Med 2009;35:1068-1074.

4. Feiner JR, Severinghaus JW, Bickler PE. Dark skin decreases the accuracy of pulse oximeters at low oxygen saturation: the effects of oximeter probe type and gender. Anesth Analg 2007;105(6 Suppl):S18-23.

5. Domingo $\mathrm{C}$, Canturri $\mathrm{E}$, Luján $\mathrm{M}$, Moreno $\mathrm{A}$, Espuelas $\mathrm{H}$, Marín $\mathrm{A}$. Transcutaneous measurement of partial pressure of carbon dioxide and oxygen saturation: validation of the SenTec monitor. Arch Bronconeumol 2006;42:246-251.

6. Cornwell AC, Weitzman ED, Marmarou A. Ambulatory and in-hospital continuous recording of sleep state and cardiorespiratory parameters in 'near miss' for the sudden infant death syndrome and control infants. Biotelem Patient Monit 1978;5:113-122.

7. Johnson P. The clinical and economic advantages of remote, communitybased physiological assessment. J Telemed Telecare 1998;4 Suppl 1:64-66.

8. Poels PJ, Schilder AG, van den Berg S, Hoes AW, F JK. Evaluation of a new device for home cardiorespiratory recording in children. Arch Otolaryngol Head Neck Surg 2003;129:1281-1284. 
9. Falor WH, Miller J, Kraus J, Fannin S, Greczanik V, Crocker N, Taylor B. Twenty-four-hour monitoring of esophagopharyngeal $\mathrm{pH}$ in outpatients. Use of four-channel pH probe and computerized system. J Thorac Cardiovasc Surg $1986 ; 91: 16-22$.

10. Furusawa EA, Filho UD, Koch VH. Home blood pressure monitoring in paediatric chronic hypertension. J Hum Hypertens 2009;23:464-469.

11. Beun AM, Gutter T, Overweg J. Home EEG and video monitoring in epilepsy: first experiences. Clin Neurol Neurosurg 1994;96:257-260.

12. Manni R, Galimberti CA, Sartori I, Politini L, Murelli R, Tartara A. Nocturnal partial seizures and arousals/awakenings from sleep: an ambulatory EEG study. Funct Neurol 1997;12:107-111.

13. Jacob SV, Morielli A, Mograss MA, Ducharme FM, Schloss MD, T BR. Home testing for pediatric obstructive sleep apnea syndrome secondary to adenotonsillar hypertrophy. Pediatr Pulmonol 1995;20:241-252.

14. Stores G, Crawford C, Selman J, Wiggs L. Home polysomnography norms for children. Technol Health Care 1998;6:231-236.

15. Acebo C, Sadeh A, Seifer R, Tzischinsky O, Wolfson AR, Hafer A, Carskadon MA. Estimating sleep patterns with activity monitoring in children and adolescents: how many nights are necessary for reliable measures? Sleep $1999 ; 22: 95-103$.

16. Quan SF, Goodwin JL, Babar SI, Kaemingk KL, Enright PL, Rosen GM, Fregosi RF, Morgan WJ. Sleep architecture in normal Caucasian and Hispanic children aged 6-11 years recorded during unattended home polysomnography: experience from the Tucson Children's Assessment of Sleep Apnea Study (TuCASA). Sleep Med 2003;4:13-19. 
17. de Jongste JC, Carraro S, Hop WC, CHARISM Study Group, Baraldi E. Daily telemonitoring of exhaled nitric oxide and symptoms in the treatment of childhood asthma. Am J Respir Crit Care Med 2009;179:93-97.

18. Midgren B. Assisted ventilation during sleep: improving respiration or sleep or both? Respir Med 2009;103:163-164.

19. Fanfulla F, Delmastro M, Berardinelli A, Lupo ND, Nava S. Effects of different ventilator settings on sleep and inspiratory effort in patients with neuromuscular disease. Am J Respir Crit Care Med 2005;172:619-624.

20. Orlikowski D, Mroue G, Prigent H, Moulin C, Bohic M, Ruquet M, Raphael JC, Annane D, Lofaso F. Automatic air-leak compensation in neuromuscular patients: a feasibility study. Respir Med 2009;103:173-179.

21. Teschler H, Stampa J, Ragette R, Konietzko N, Berthon-Jones M. Effect of mouth leak on effectiveness of nasal bilevel ventilatory assistance and sleep architecture. Eur Respir J 1999;14:1251-1257.

22. Borel JC, Sabil A, Janssens JP, Couteau M, Boulon L, Lévy P, Pépin JL. Intentional leaks in industrial masks have a significant impact on efficacy of bilevel noninvasive ventilation: a bench test study. Chest 2009;135:669-677. 


\section{Legend of the figures}

\section{Figure 1}

Individual mean (left figure) and minimal (right figure) pulse oximetry $\left(\mathrm{SpO}_{2}\right)$ values observed at home and in the hospital in patients with neuromuscular disease (black circles) and with other disorders (open circles).

For mean $\mathrm{SpO}_{2}$, regression lines are represented (plain for patients with neuromuscular disease $(r=0.494, p=0.061)$ and dashed for patients with other disorders $(r=0.608, p=0.028))$. Several patients having similar $\mathrm{SpO}_{2}$ values, only 15 of the 28 spots are visible.

For minimal $\mathrm{SpO}_{2}$, regression lines are represented (plain for patients with neuromuscular disease $(r=0.340, p=N S)$ and dashed for patients with other disorders $(r=0.547, p=N S)$. Two patients having similar $\mathrm{SpO}_{2}$ values, only 27 of the 28 spots are visible.

\section{Figure 2}

Comparison of percentage of nocturnal recording time spent with a pulse oximetry $\left(\mathrm{SpO}_{2}\right)>95 \%$, between 94 and 95\%, between 93 and $92 \%$, and < $92 \%$ during the recordings performed in the hospital (black bars) and at home (grey bars).

\section{Figure 3}

Individual mean (left figure) and maximal (right figure) transcutaneous carbon dioxide $\left(\mathrm{PtcCO}_{2}\right)$ values observed at home and in the hospital in patients with neuromuscular disease (black circles) and with other disorders (open circles). 
For mean $\mathrm{PtcCO}_{2}$, regression lines are represented (plain for patients with neuromuscular disease $(r=0.647, p=0.009)$ and dashed for patients with other disorders $(r=0.564, p=0.037))$

For maximal $\mathrm{PtcCO}_{2}$, regression lines are represented (plain for patients with neuromuscular disease $(r=0.417, p=N S)$ and dashed for patients with other disorders $(r=0.636, p=0.014)$.

Three patients having similar $\mathrm{PtcCO}_{2}$ values, only 27 of the 29 spots are visible.

\section{Figure 4}

Comparison of percentage of nocturnal recording time spent with a $\mathrm{PtcCO}_{2}>50$ $\mathrm{mmHg}$ and $\leq 50 \mathrm{mmHg}$ during the recordings performed in the hospital (black bars) and at home (grey bars). 
Table 1: Characteristics of the patients.

\begin{tabular}{|c|c|}
\hline & $\begin{array}{c}\text { patients } \\
\mathrm{n}=24\end{array}$ \\
\hline Age (years) & $10(4-19)$ \\
\hline Male / Female & $17 / 7$ \\
\hline Primary disease & 11 \\
neuromuscular disease & 3 \\
lung disease & 9 \\
upper airway obstruction & 1 \\
central hypoventilation & $20(3-62)$ \\
\hline Duration of NPPV (months) & 10 \\
\hline Ventilatory mode & 5 \\
AC/VT & 9 \\
PS & 18 \\
Bilevel positive pressure & 3 \\
\hline Interface & 3 \\
industrial nasal mask & \\
industrial face mask & \\
custom made nasal mask & \\
\hline
\end{tabular}

Data are given as median (range).

Abbreviations: NPPV: noninvasive positive pressure ventilation, AC/VT: assist control / volume targeted ventilation, PS: pressure support ventilation. 
Table 2: Results of the recordings performed in the hospital and at home in the patients with neuromuscular disease and those with other disorders.

\begin{tabular}{|c|c|c|c|c|c|c|}
\hline & \multicolumn{2}{|c|}{$\begin{array}{c}\text { Recordings in patients } \\
\text { with neuromuscular } \\
\text { disease } \\
n=15\end{array}$} & \multirow[t]{2}{*}{$p$} & \multicolumn{2}{|c|}{$\begin{array}{l}\text { Recordings in patients } \\
\text { with other disorders } \\
n=14\end{array}$} & \multirow[t]{2}{*}{$p$} \\
\hline & $\begin{array}{l}\text { Hospital } \\
\text { recordings }\end{array}$ & $\begin{array}{l}\text { Home } \\
\text { recordings }\end{array}$ & & $\begin{array}{l}\text { Hospital } \\
\text { recordings }\end{array}$ & $\begin{array}{l}\text { Home } \\
\text { recordings }\end{array}$ & \\
\hline $\begin{array}{l}\text { Median value of the } \\
\text { individual mean } \mathrm{SpO}_{2}(\%)\end{array}$ & $\begin{array}{c}98 \\
(94-99)\end{array}$ & $\begin{array}{c}98 \\
(97-100)\end{array}$ & 0.49 & $\begin{array}{c}96 \\
(93-99)\end{array}$ & $\begin{array}{c}98 \\
(95-99)\end{array}$ & 0.06 \\
\hline $\begin{array}{c}\text { Median value of the } \\
\text { individual minimal } \mathrm{SpO}_{2}(\%)\end{array}$ & $\begin{array}{c}91 \\
(82-97)\end{array}$ & $\begin{array}{c}94 \\
(75-97)\end{array}$ & 0.65 & $\begin{array}{c}91 \\
(80-93)\end{array}$ & $\begin{array}{c}89 \\
(87-93)\end{array}$ & 0.72 \\
\hline $\begin{array}{l}\text { Median value of the } \\
\text { individual mean } \mathrm{PtcCO}_{2} \\
\qquad(\mathrm{mmHg})\end{array}$ & $\begin{array}{c}40 \\
(32-51)\end{array}$ & $\begin{array}{c}40 \\
(32-51)\end{array}$ & 0.65 & $\begin{array}{c}45 \\
(37-53)\end{array}$ & $\begin{array}{c}43 \\
(33-55)\end{array}$ & 0.65 \\
\hline $\begin{array}{l}\text { Median value of the } \\
\text { individual maximal } \mathrm{PtcCO}_{2} \\
\qquad(\mathrm{mmHg})\end{array}$ & $\begin{array}{c}48 \\
(37-62)\end{array}$ & $\begin{array}{c}45 \\
(37-56)\end{array}$ & 0.07 & $\begin{array}{c}49 \\
(41-60)\end{array}$ & $\begin{array}{c}47 \\
(41-56)\end{array}$ & 0.07 \\
\hline
\end{tabular}

Data are expressed as median (range).

$\mathrm{SpO}_{2}$ : pulse oximetry, $\mathrm{PtcCO}_{2}$ : transcutaneous carbon dioxide. 
Figure 1
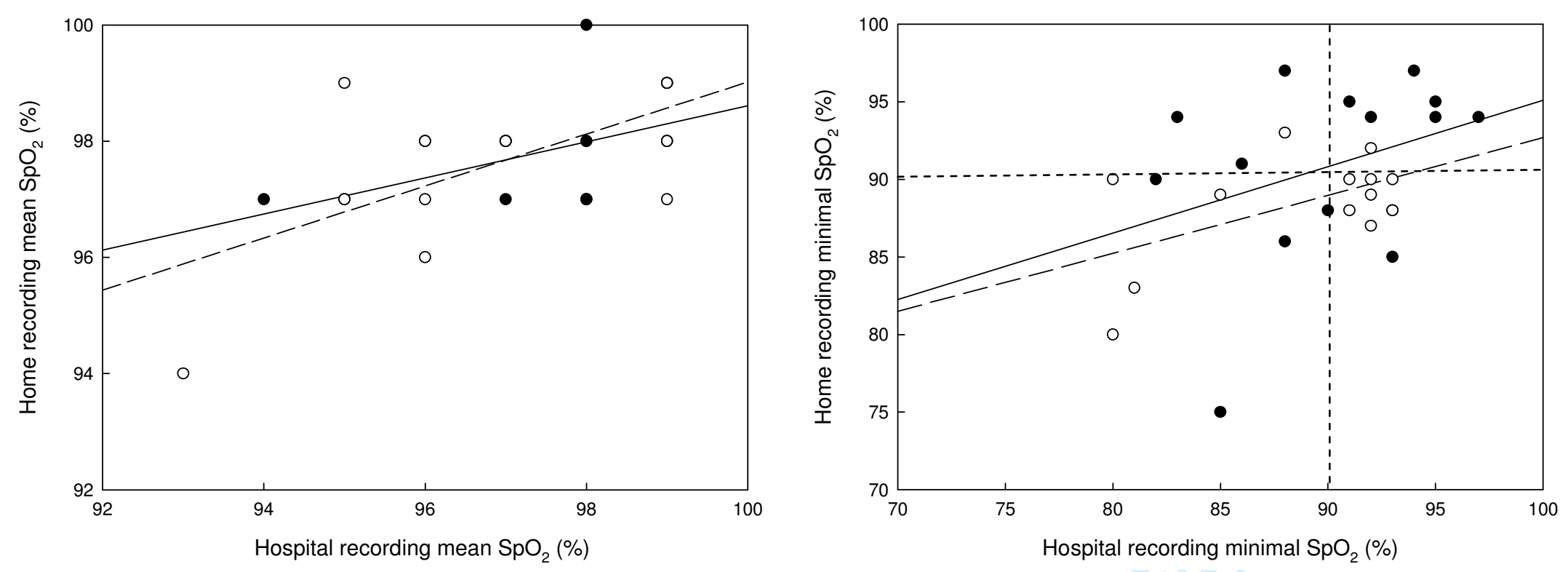

John Wiley \& Sons, Inc. 
Figure 2
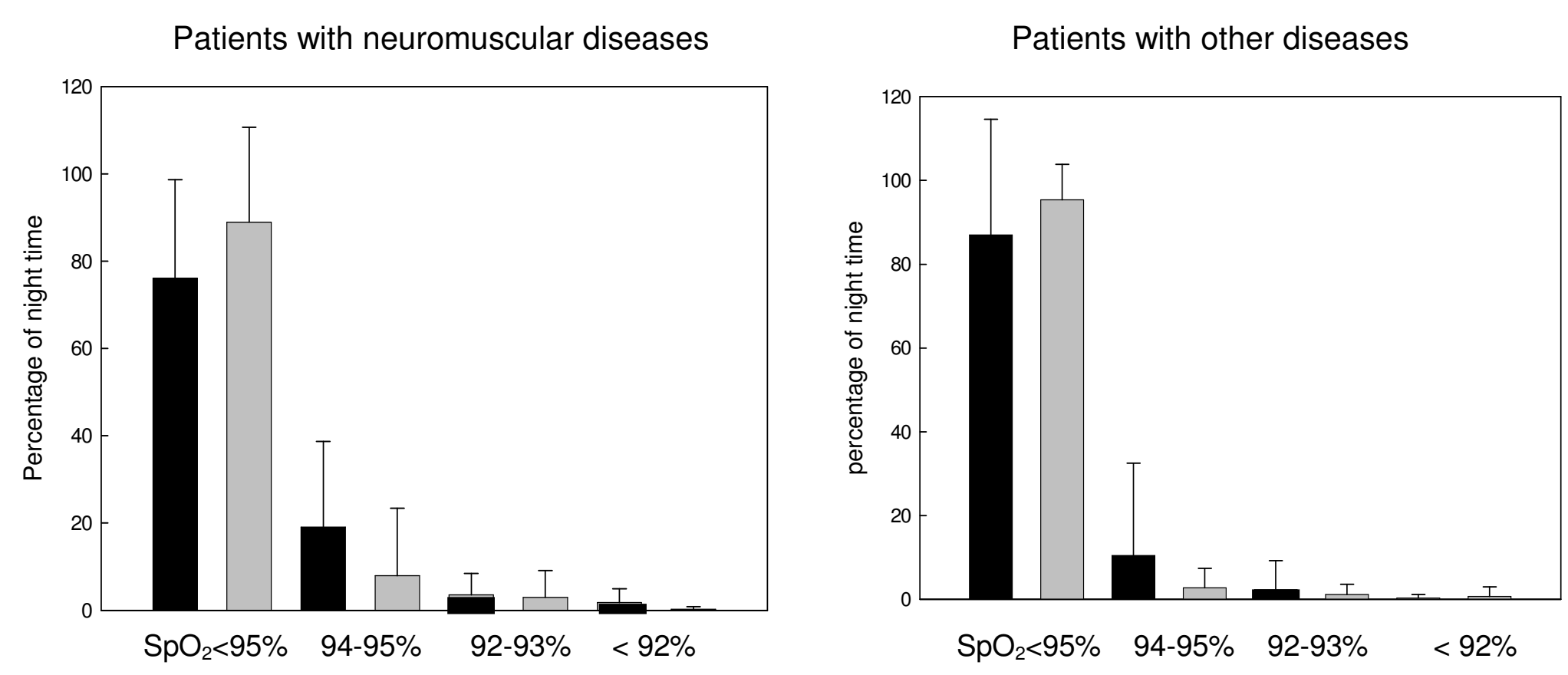
Figure 3
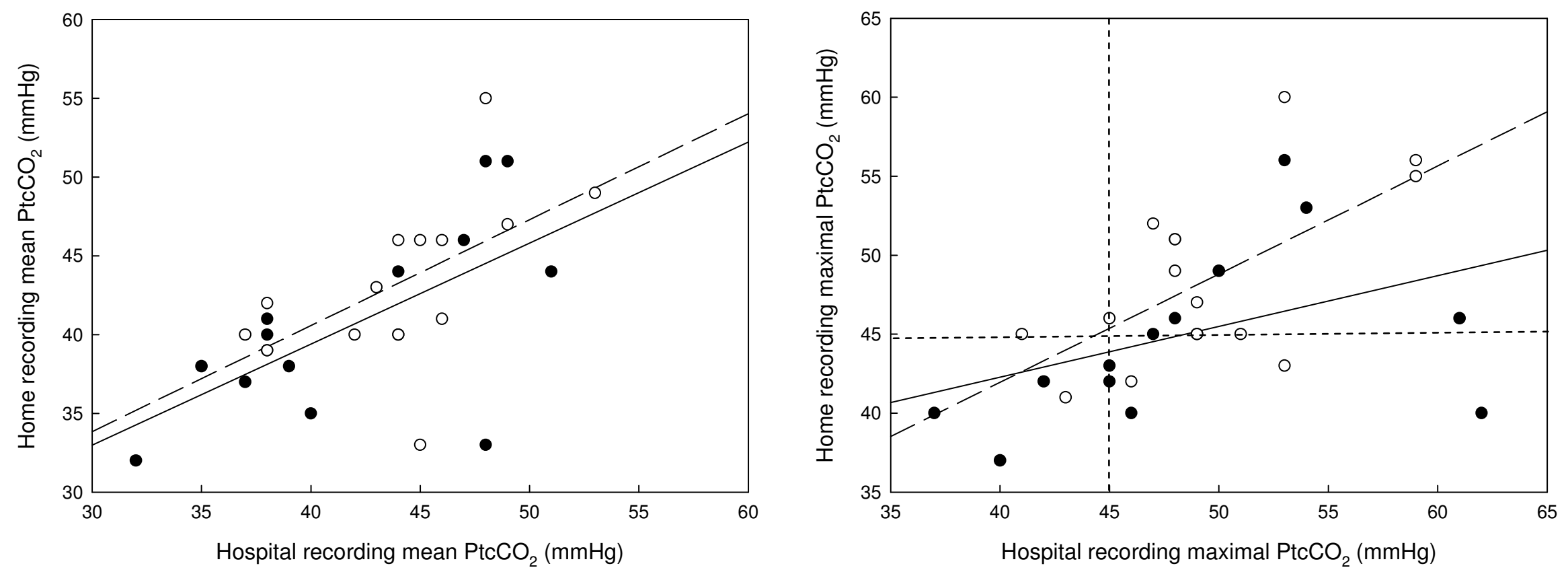

John Wiley \& Sons, Inc. 
Figure 4
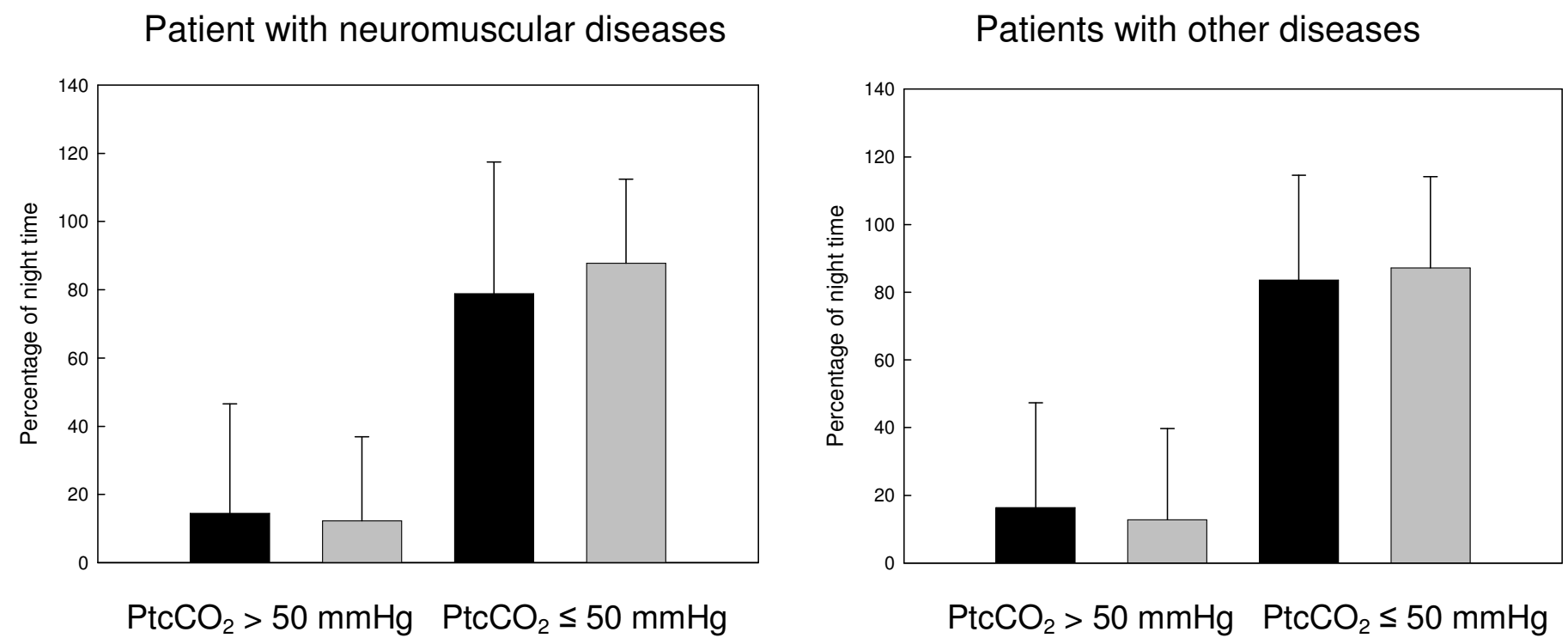

John Wiley \& Sons, Inc. 